\title{
O FATOR ECONÔMICO DO CONHECIMENTO NA SOCIEDADE ATUAL
}

\author{
The Economic Factor in the Knowledge Society Present
}

\author{
Paulo Henrique Levecke ${ }^{1}$ \\ Alexandre Carvalho Acosta ${ }^{2}$ \\ Recebido em: 18 out. 2017 \\ Aceito em: 09 ago. 2018
}

Resumo: O conhecimento constitui-se, hodiernamente, como um fator de sucesso para as organizações. Na sociedade do conhecimento e da informação, o conhecimento se transforma no fator-chave da economia e o principal determinante da mudança ocupacional. Os trabalhadores necessitam se adaptar as novas exigências em termos de educação e, por serem o capital humano da organização, também adquirem relevância uma vez que são responsáveis por todo o capital intelectual que a organização possui, ademais de produzirem, compartilharem e transformarem o conhecimento em ação e resultados. Nesse contexto, a Gestão do Conhecimento se configura importante metodologia à disposição das organizações que contribui para criar, compartilhar e disseminar o conhecimento no intento de auxiliar a organização adversar da melhor forma possível às forças que o ambiente exerce sobre a organização. Em virtude da importância do conhecimento, a Gestão do Conhecimento tem adquirido espaço em meio à educação superior enquanto disciplina. O modelo de Gestão do Conhecimento deve ser interdisciplinar e reflexivo. Na Sociedade do Conhecimento, relação entre organização e colaborador não se deve configurar de forma unidirecional, mas sim permitir a participação e instaurar cultura corporativa estimuladora da criatividade e da inovação tecnológica.

Palavras-Chave: Sociedade do Conhecimento. Gestão do conhecimento. Perfil profissional.

Abstract: The knowledge is constituted, in our times, as a success factor for organizations. In the knowledge society and information, knowledge becomes the key factor in the economy and the main determinant of occupational change. Workers need to adapt to new requirements in terms of education and because they are the organization's human capital, also become rele-vant since they are responsible for all the intellectual capital that the organization has, in addi-tion to produce, share and transform knowledge into action and results. In this context, Knowledge Management is important to set methodology to the organizations helping to cre-ate, share and disseminate knowledge

\footnotetext{
${ }^{1}$ Especialista em Ciências Sociais Aplicadas Área de Concentração: Contabilidade Gerencial e Administração Financeira. Professor titular da Fundação Universidade Alto Vale do Rio do Peixe - UNIARP e Coordenador do Curso de Ciências Contábeis. E-mail: contabeis@uniarp.edu.br.

2 Doutor pela Universidad Nacional Tres de Febrero (UNTREF); pós-graduado em Gestão Educacional pela Pontifícia Universidade Católica (PUC-RS); pós-graduado em Marketing e Vendas pela Universidade Alto Vale do Rio do Peixe (UNIARP); Graduado em Comunicação Social Jornalismo pela Universidade Regional do Noroeste do Estado do Rio Grande do Sul (UNIJUÍ); Graduando do Curso de Administração da Universidade Alto Vale do Rio do Peixe (UNIARP). E-mail: alexandre@alexandreacosta.com.
} 
in an attempt to help the organization as well as possi-ble adverse forces that the environment exerts on the organization. Given the importance of knowledge, Knowledge Management has acquired space in the midst of higher education as a discipline. The model of Knowledge Management should be interdisciplinary and reflective. In the Knowledge Society, the relationship between organization and employee must not be set in a unidirectional way, but to enable the participation and introduce corporate culture that stimulates creativity and innovation.

Keywords: Society and Knowledge Management. Professional profile.

\section{INTRODUÇÃO}

A formação do conhecimento se constitui como um investimento fundamental nos países desenvolvidos, e tem recebido cada vez mais destaque nas organizações. O retorno que um país ou uma entidade obtém sobre o conhecimento, na atualidade, representa um fator determinante de sua exitosidade.

Destarte, infere-se, em um grau cada vez maior, que o conhecimento se torna decisivo para o sucesso econômico e social de uma organização. E a precípua disparidade entre países e entre organizações diz respeito à capacidade de produzir conhecimento. Isso significa que o conhecimento se transformou em um elemento fundamental da dinâmica da nova ordem mundial: conhecimento e informação são, hodiernamente, recursos estratégicos e os agentes transformadores da sociedade.

Kumar (1997) acrescenta que na estrutura da sociedade da informação, o conhecimento não apenas determina, em um grau sem precedentes, a inovação técnica e o crescimento econômico, mas se torna a atividade-chave da economia e a principal determinante da modificação ocupacional.

Associada a essa nova realidade produtiva tem-se o desenvolvimento das Tecnologias de Informação e Comunicação (TICs), as quais facilitam a transmissão da informação para gerar conhecimentos novos a todo instante. Com isso, tem-se o advento da sociedade do conhecimento. Esta, consoante o magistério de Kumar (1997), consiste no resultado de um processo de transformação social, onde a informação e o conhecimento adquirem relevância central. O axioma central deste modelo civilizacional emergente reside na evolução no sentido do fortalecimento do setor de serviços de serviços e o crescimento célere de ensejos de emprego para profissionais com sólida formação.

Fleury e Fleury (2004) pontuam que, na economia pautada em conhecimento, o que mais adiciona valor são as atividades inteligentes, enquanto as atividades rotineiras, manuais, passam a ser cada vez menos importantes. O labor intelectual interessa sempre mais e que é cada vez mais incentivado. Destarte, as organizações que operam com base no novo paradigma do conhecimento, focam as atividades que sejam realmente agregadoras de valor, aquelas que são mais intensivas em inteligência. 
Em meio a essa realidade, percebe-se um aumento constante do conhecimento, o qual não é somente quantitativo, mas também qualitativo. Enquanto que os meios de comunicação antigos transmitiam a mensagem de forma padronizada a espectadores de massa uniformes, por meio das novas tecnologias de comunicação viabilizou-se a concentração, a segmentação e a divisão de transmissores e receptores em unidades separadas e descontínuas. Desse modo, é possível processar uma informação, recuperá-la ou selecioná-la com o fim de satisfazer as necessidades mais especializadas e individualizadas.

Essa importância do conhecimento também tem incentivado modificação ocupacional das pessoas. A quantidade de colaboradores empregados no setor de produção da informação tem aumentado consideravelmente, gerando a produção em massa informação, à semelhança da produção de um objeto físico de consumo. Isso redunda na modificação dos mecanismos estruturais da produção.

Kumar (1997, p. 24) sustenta que "a própria fonte da criação de riqueza e os fatores determinantes da produção" são modificados. O trabalho e o capital, que até se constituíam como as variáveis básicas da sociedade industrial, são substituídos pela informação e pelo conhecimento. A informação é uma mercadoria e o caráter fundamental de uma infraestrutura, sendo que o capital formado pelo conhecimento exercerá o predomínio sobre o capital material na estrutura da economia.

Emerge, por conseguinte, que o conhecimento e as tecnologias de informação influenciam diretamente o mercado de trabalho. Essa influência se dá pelo aumento do conteúdo de conhecimentos do trabalho existente, ou seja, a nova tecnologia adiciona mais em termos de qualificação dos trabalhadores, além de promover a criação e a expansão de novos tipos de trabalho no setor do conhecimento, de forma que trabalhadores da informação serão predominantes na economia.

Como se observa, a sociedade atual configura-se tal modo que toda ela gira em torno do conhecimento. Essa importância no âmbito de organizações e países implica a necessidade de desenvolver formas de gerir o mesmo. O conhecimento precisa ser produzido, organizado, armazenado e utilizado em favor da organização da mais eficaz forma possível.

No intento de proporcionar o melhor aproveitamento do conhecimento emergiu a Gestão do Conhecimento, metodologia à disposição da organização que objetiva auxiliar a organização a obter todas as vantagens possíveis da aplicação do conhecimento. A Gestão do Conhecimento pode ser concebida como uma metodologia empresarial que envolve todo o processo organizacional direcionado para combinação ideal do processamento de dados e informações, das TICs e da criatividade dos colaboradores para otimizar o emprego de seu acervo tecnológico.

Entrementes em que a Gestão do Conhecimento torna-se metodologia indispensável dentro para os países e organizações, para que aproveitem adequadamente seu capital 
intelectual, ela também adquire espaço em meio no âmbito universitário. Para que possa se efetivar, fazem-se pessoas que tenham conhecimento acerca das atividades relacionadas à Gestão do Conhecimento, ou seja, pessoas habilitadas na disciplina.

\section{INTERAÇÃO COM O CAPITAL INTELECTUAL}

A Gestão do Conhecimento também se encontra diretamente vinculada ao Capital Intelectual. Todos esses procedimentos são indispensáveis para que uma organização possa se transformar em uma organização do conhecimento, criando, armazenando e distribuindo conhecimento no intento de otimizar seus resultados

O capital intelectual, no entender de Brooking (1996 apud ANTUNES, 2000, p. 78), é "uma combinação de ativos intangíveis, frutos das mudanças nas áreas da tecnologia da informação, mídia e comunicação, que trazem benefícios intangíveis para as empresas e que capacitam seu funcionamento".

Antunes (2000) divide-o em quatro categorias:

a) ativos de mercado: é o potencial em virtude dos intangíveis, que estão relacionados ao mercado, como marca, clientes, lealdade dos clientes, negócios recorrentes, negócios em andamento, canais de distribuição, franquias, entre outros;

b) ativos humanos: diz respeito aos benefícios que os indivíduos pode proporcionar as organizações através de sua expertise, criatividade, conhecimento, habilidade para resolver problemas, tudo abordado de modo coletivo e dinâmico;

c) ativos de propriedade intelectual: são aqueles ativos que exigem a proteção legal para proporcionarem às organizações benefícios, como o know-how, segredos industriais, copyright, patentes, designers, entre outros;

d) ativos de infra-estrutura: compreende as tecnologias, as metodologias e os processos empregados como cultura, sistema de informação, métodos gerenciais, aceitação de risco e banco de dados de clientes.

O capital humano ou ativo humano, segundo Zabot e Silva (2002), diz respeito àquelas pessoas estudadas e especializadas, que são importantes recursos para a empresa, uma vez que coordenam todo o processo de geração e compartilhamento do conhecimento. Os autores acrescentam que tido como a característica mais marcante da era do conhecimento, o surgimento do capital humano aparece como a força dominante da economia. Embora na sociedade industrial o capital físico e o financeiro se constituíam em fatores críticos para o sucesso, na economia do conhecimento a importância relativa do capital físico diminui à medida que a tecnologia se torna mais barata e a qualificação, o conhecimento e as habilidades das pessoas crescem em importância.

Além disso, enquanto na sociedade industrial a educação era direcionada de forma exclusiva para a alfabetização e o provimento de treinamento técnica, na era do conhecimento e da informação a exigência da educação torna-se universal e os níveis de educação crescem para as novas áreas de conhecimentos que requerem mais treinamento e educação atualizada 
para sua aplicação (ZABOT; SILVA, 2002).

O capital humano se constitui como a fonte dos ativos intangíveis em uma organização. De acordo com Zabot e Silva (2002), o fato de as pessoas serem os únicos verdadeiros agentes na empresa, fonte dos ativos intangíveis, e de essas pessoas estarem constantemente direcionando seus esforços em dois sentidos, para fora da empresa no relacionamento com os clientes, e para dentro, mantendo e construindo a organização, permite que tais ativos sejam classificados como um grupo de três elementos:

a) Competência das pessoas: é considerada ativo intangível, pois, mesmo que não possa ser propriedade de ninguém, exceto da própria pessoa, é inviável conceber uma organização sem pessoas. Em certas organizações do conhecimento existem poucos equipamentos e, como apenas as pessoas podem agir, elas tornam-se tanto os mentores do equipamento quanto os próprios equipamentos;

b) Estrutura interna: engloba conceitos, patentes, modelos e sistemas, bem como a cultura organizacional. Uma organização e sua estrutura são resultado da criação das pessoas, por meio da interação mútua, desenvolvendo, desse modo, o ambiente; e

c) Estrutura externa: está relacionada não apenas com às relações com clientes e fornecedores, mas também a marcas e à própria imagem da empresa e sua reputação. O valor desses ativos é determinado pelo grau de satisfação com que a empresa soluciona os problemas de seus clientes, algo também difícil de quantificar em termos monetários e mutável com o passar do tempo.

O desenvolvimento do capital humano está centrado, sobretudo, no desenvolvimento das competências. Em uma sociedade na qual a competitividade cresce sempre mais, a competência torna-se um diferencial e um requisito para um desempenho satisfatório das pessoas e das organizações. Uma competência é uma combinação de conhecimentos e comportamentos, conhecimentos estes que reúnem características, tais como, formação, treinamento, experiência, auto-desenvolvimento, habilidades, interesses e vontade (RESENDE, 2003).

Nas organizações do conhecimento, algumas competências são indispensáveis: aprender a aprender; comunicação e colaboração (espírito de equipe); raciocínio criativo e resolução de problemas, esperando-se que os colaboradores descubram por si próprios, como agilizar seu trabalho; conhecimento tecnológico, conhecimentos e habilidades globais; desenvolvimento de liderança e auto-gerenciamento de carreira.

Importa salientar que mensurar e contabilizar o capital intelectual se constitui em mister de complexa efetivação. Conforme salienta Sveiby (1998 apud LARA, 2004), as organizações não negociam seus ativos intangíveis, por isso o valor dos mesmos não pode ser deduzido das transações de mercado de rotina como o valor dos ativos tangíveis. O valor somente aparece de forma indireta no mercado de ações ou quando uma organização troca de mãos. O mercado de ações oferece uma valorização diária dos ativos das organizações cotadas na bolsa e faz uma estimativa aproximada do fundo de comércio que seria acrescentado no caso da aquisição. 


\section{MOTIVAÇÃO DO FATOR HUMANO E DESEMPENHO ORGANIZACIONAL}

Como maneira de melhorar a eficiência dos produtos já existentes, as novas tecnologias vêm sendo adotadas também para produzir novos produtos e serviços, ou, ainda, como incremento do rendimento e também da produtividade das organizações. Com efeito, a tecnologia constitui-se em um instrumento fundamental que afeta as relações sociais, as relações de dominação ou de poder organizacional e, assim sendo, seus impactos não podem ficar sem serem observados e analisados (RATTNER, 1985).

Com a implementação da mudança organizacional, os processos, a estrutura e os comportamentos, podem ser afetados. Podendo ser alterado também o processo decisório, ocorrendo da mesma maneira, com os canais de comunicação. Segundo Basil e Cook (1978), a mudança institucional e estrutural tem impactos múltiplos, variando da eliminação do meio de vida do trabalhador, até a completa reorientação da sociedade.

Os autores supra citados destacam ainda que a mudança tecnológica libertou o homem de devotar todo o seu tempo e energia à sobrevivência física. Criou grandes excessos de bens materiais, permitindo a esse dedicar tempo e recursos a objetivos educacionais e culturais para intensificar o seu bem estar físico em sociedades industriais.

Essa nova liberdade do homem, dos problemas de sobrevivência e seu desenvolvimento como um ser instruído, com todos os conhecimentos ou experiências passadas do mundo ao alcance da mão, resultou em maciças mudanças sociais e comportamentais do século XIX e XX.

Dentre as várias mutações organizacionais que ocorreram recentemente, uma das que despertou maior atenção parece ser a tecnológica. Nos termos da clarificação de Rodrigues et al. (1986), a difusão e a multiplicação da tecnologia da microeletrônica cresceram, com uma enorme rapidez, no setor industrial, e de forma ainda mais surpreendente no setor de serviços. Dentre algumas vantagens dessa tecnologia que permitirão a sua aplicação às mais diferentes situações, a autora pontua: tamanho, custo, rapidez e baixo consumo de energia.

A relação entre a tecnologia utilizada, a estrutura e o desempenho organizacional vêm sendo intensamente estudada e debatida pelos pesquisadores que procuram melhor entender esta questão. Estudos teórico-empíricos que relatam sobre a evolução histórica do homem e seus meios de produção vêm tentando demonstrar a relação direta existente entre a tecnologia e diferentes variáveis organizacionais. Atendo-se à história do desenvolvimento tecnológico na produção de bens e serviços, o seu relacionamento é observado de forma direta com as modificações nas formas de organização das instituições existentes.

Desde a produção artesanal, transitando pela primeira revolução industrial, que é o instante em que ocorre o surgimento de máquinas automáticas e semi-automáticas na produção, até os tempos atuais da automação, as organizações têm-se transformado de 
simples unidades fabris de trabalho manual, com preocupação principal na qualidade do produto, em sistemas mais sofisticados, onde o operário torna-se um fiscalizador/condutor ou analista/programador de máquinas automatizadas orientado pela idéia de máxima produtividade (CANTANHEDE, 1980).

Um dos estudiosos do impacto da tecnologia na organização, Woodward (apud HALL, 1984), demonstra que a natureza da tecnologia afeta de maneira fundamental as estruturas administrativas das empresas, atingindo aspectos como o número de níveis na hierarquia administrativa, a amplitude do controle dos supervisores de primeiro escalão e a proporção de gerentes e supervisores em relação ao restante do pessoal. Não apenas a estrutura é afetada, mas igualmente o sucesso ou a eficácia da organização que se relaciona com o 'encaixe' entre a tecnologia e a estrutura.

Seguindo-se a mesma linha de relacionamento entre tecnologia, estrutura de tarefas e nível de desempenho, uma estrutura organizacional 'flexível' é mais apropriada para um ambiente tecnológico em mudança, e, por outro lado, uma estrutura organizacional 'rígida' para um ambiente tecnológico estável.

Destarte, em consonância com o magistério da lavra de McKenna (1999), observa-se que a revolução tecnológica da última metade do século XX determinou colossais modificações econômicas e industriais. Ao trabalhar com diferentes organizações, esse autor observou que, embora cada empresa e setor apresentasse sua própria base de conhecimentos, todos sofriam grande influência das mudanças tecnológicas. A tecnologia e seus efeitos atingiram tudo o que é realizado, afetando a vida pessoal e profissional de todos.

\section{TECNOLOGIA E CONHECIMENTO}

Uma nova tecnologia introduzida na organização, sempre acaba por gerar alguma espécie de impacto, segundo Weick (1991 apud GONÇALVES, 1994); por conseguinte, a nova tecnologia não é essencialmente a que se baseia em computadores, nem é aquela completamente inédita, mas sempre é a tecnologia nova para a organização em análise, posto que ela não seja nova para o mercado, porém, utilizada em substituição a procedimentos anteriormente adotados na organização.

Ainda salienta Gonçalves (1994) que uma nova tecnologia pode ser tida como uma mudança de procedimentos manuais para o uso de máquinas de datilografia e de calcular, que foram substituídas por microcomputadores, e, mais adiante, por redes de computadores. Tal substituição de tecnologias exige que as pessoas envolvidas adquiram um aprendizado para a utilização destes equipamentos e procedimentos.

O mesmo autor continua, afirmando que, ademais de presente em todas as formas de organização, a tecnologia é do mesmo modo uma potente força, podendo estender as 
capacitações humanas. A revolução industrial utilizou a tecnologia para ampliar a capacidade física do homem na realização de trabalhos e a revolução da informática está estendendo a capacidade no instante de realizar trabalho mental e redistribuindo o tempo que é dedicado à realização das diversas atividades.

As aplicações da informática nas organizações variam bastante de acordo com cada circunstância e da mesma maneira acontece com seus impactos. As influências provocadas por esta tecnologia têm estabelecido configurações novas do trabalho que são responsáveis por novos desenhos organizacionais. Tal fato se dá, tanto em termos de processo decisório, estrutura de poder, divisão do trabalho, ou, ainda, comportamentos e atitudes, diferentes variáveis estão sendo afetadas pela adoção da nova tecnologia.

Champion (1979) destaca modificações processuais primordiais nas organizações, que estão associadas ao aperfeiçoamento em tecnologia que são:

1) tomada de decisão;

2) quantidade de níveis de supervisão;

3) tipo de supervisão;

4) coordenação entre as tarefas de trabalho;

5) segurança na função;

6) status da função.

Como maneira de melhor entendimento desse tema, é importante citar alguns teóricos motivacionais. Nesse contexto, Frederick Herzberg, desenvolveu na década de 50 o modelo de motivação que se deu por meio de uma pesquisa realizada com engenheiros e contadores. O autor concluiu que dois fatores influenciam a motivação, primeiro são os fatores de manutenção e segundo são os fatores de motivação.

Para Davis e Newstrom (1992) fatores motivacionais tais como realização e responsabilidade estão, nomeadamente relacionados com o trabalho em si, enquanto que o desempenho do trabalhador o seu reconhecimento e crescimento estão por ele assegurados. Os fatores de motivação na sua maior parte estão centralizados no trabalho; estando ligados dessa maneira com o seu conteúdo. Por outro lado, os fatores de manutenção estão principalmente pautados ao contexto de trabalho, uma vez que eles se encontram mais ligados com o ambiente que envolve o trabalho.

Tal disparidade entre o conteúdo do trabalho e o seu contexto é assaz significativa. Uma vez que mostra que os empregados estão primária e fortemente motivados por aquilo que fazem para si mesmo. Quando assumem a responsabilidade ou ganham reconhecimento por meio do seu próprio comportamento se acham fortemente motivados (DAVIS; NEWSTROM, 1992).

Em consonância com o magistério lavra de Hesketh (1977, p. 100), “o trabalho de 
Herzberg apresenta o que ele chama de teoria bifatorial de motivação". Esse autor também destaca que fatores higiênicos - atratividade de instalações físicas e bons salários criam insatisfação caso não existam, mas a sua presença, sem embargo, não cria motivação. Já os fatores motivacionais, tais como repto, responsabilidade e reconhecimento, são necessários para que essa seja estimulada.

Os conceitos fundamentais de comportamento organizacional se relacionam diretamente com a natureza das organizações, isso quer dizer, com diferenças individuais, comportamento motivado e valor da pessoa, e ainda, à natureza das organizações, isto é, seu sistema social e interesse mútuo (DAVIS; NEWSTROM, 1992).

Maslow e Herzberg (apud VIEIRA, 1996) consideram ainda que existe qualidade de vida no trabalho, na medida em que os indivíduos têm condições de satisfazer suas necessidades pessoais, através da organização onde atuam.

Dependendo do desenvolvimento pessoal e da posição percebida na vida, as pessoas ligam determinados valores a itens ou ações oferecidas por uma determinada empresa. Essa simplificação da teoria de Maslow, no entendimento de Towsend (1991), explica por que um programa que ofereça uma combinação de reconhecimento, gratidão e celebração é tão bemsucedido.

Para determinadas pessoas, o reconhecimento público ou do seu valor para a empresa será o principal motivador. Enquanto que para outras, as recompensas materiais são a maior fonte de inspiração e motivação. E, para outras, ainda, a celebração que demonstre reconhecimento e gratidão será a chave que as liga. Para a maioria, uma combinação é o que funciona melhor (TOWSEND, 1991).

No juízo de Brocka e Brocka (1994), o modelo da hierarquia das necessidades de Maslow propõe fundamentalmente que as pessoas possuem necessidades que desejam satisfazer e que, aquelas que já foram atendidas não tem mais a força motivacional das necessidades não satisfeitas.

A respeito, Hesketh (1977) argumenta que, o trabalho de Maslow estabeleceu dois postulados primordiais a respeito da motivação humana. O primeiro é o de que as necessidades psicológicas do homem podem ser vistas através de uma perspectiva hierárquica.

Aquelas necessidades de ordem inferior, isto é, necessidades de ordem física e estabilidade, devem ser satisfeitas em certo grau antes que as necessidades de ordem superior - necessidades de auto-estima e auto-realização - se tornem ativadas.

Por sua vez, o segundo postulado versa a respeito da noção de que uma necessidade satisfeita deixa de ser um fator motivador de comportamento. Descobertas como estas ajudam a entender porque é que um aumento salarial pode ser de valor motivacional marginal. O ser humano está em níveis diferentes na hierarquia motivacional em diferentes épocas. 
A motivação é o resultado da autonomia outorgada ao profisscional. O que motiva as pessoas é o que elas fazem. A motivação resulta da possibilidade de agir, se sentir realizado e ser reconhecido por seus atos.

De acordo com Teboul (1991), o "algo mais" da motivação somente aparece quando as pessoas têm condições de realizar-se e ser apreciadas. As pessoas motivadas dispõem de um gerador autônomo. Elas são colocadas em movimento a partir do interior, e não do exterior através de uma situação. A participação nos resultados procura menos colocar em movimento e mais recompensar o movimento.

\section{CONSIDERAÇÕES FINAIS}

O conhecimento, caracterizado por sua auto-reprodução e difusão, bem como substituição e compartilhamento, constitui-se na peça central que move a complexa civilização coetânea. Diferencia-se dos dados, que são as evidências mais básicas de uma investigação, aqueles aspectos de um fenômeno estudado que um determinado investigador pôde captar ou registrar, bem como da informação, que pode ser interpretada como um dado trabalhado, útil, tratado, o qual possui um valor significativo atribuído ou agregado a ele e com um sentido natural e lógico para quem usa a informação.

A Gestão do Conhecimento envolve o conhecimento propriamente dito, mas também dados e informações, uma vez que estes últimos se constituem como a base de produção do conhecimento. O conhecimento é definido do seguinte modo pelos diversos autores estudados: um conjunto de argumentos e explicações que interpretam um conjunto de informações; uma combinação de instintos, idéias, informações, regras e procedimentos responsáveis por guiar ações e decisões, abrangendo experiências vivenciadas, valores, informação contextual, entre outros fatores que proporcionam uma estrutura para a avaliação e incorporação de novas experiências e informações; e uma capacidade de aplicar a informação a um trabalho ou a um resultado específico.

A construção e a utilização desse conhecimento compreende um repto para as organizações, porquanto este se encontra disperso no contexto organizacional e necessita ser localizado, organizado e gerido para que se transforme num bem da organização e, assim, contribua para a sustentabilidade organizacional.

Nesse sentido, amealha relevância a Gestão do Conhecimento, que pode ser entendida como metodologia englobadora de todo o processo organizacional, visando a alcançar a combinação sinérgica do processamento de dados e informações, da tecnologia da informática e da criatividade do ser humano. Essa metodologia deve proporcionar à empresa sua constante adaptação a um meio ambiente em evolução permanente, pressupondo a identificação, a análise, a interpretação e a avaliação dos conhecimentos específicos para 
empregá-los na otimização dos recursos da organização e no atendimento das necessidades de sua ambiência exógena.

A Gestão do Conhecimento permite gerenciar de modo inteligente, ordenado, sistematizado e eficaz tudo aquilo que a organização sabe lhe agrega valor. E o que agrega esse valor são os processos, produtos, matérias-primas, informações contidas nos documentos, nas publicações, a experiência, a criatividade, as habilidades, que fazem parte do conhecimento tácito, etc. A gestão permite, assim, gerenciar o processo de criação e disseminação do conhecimento dentro de uma organização, incorporando-o a produtos, serviços e sistemas.

A criação ou o desenvolvimento do conhecimento deve ser entendido como um processo que amplia o conhecimento desenvolvido por pessoas no contexto organizacional. Essa criação deriva da interação existente entre o conhecimento tácito e o explícito, implicando quatro formas de conversão do conhecimento: do tácito para o tácito, quando se dá o compartilhamento de experiências; do tácito para o explícito, ocorrendo a articulação do conhecimento tácito em conceitos explícitos, isto é, desenvolve-se um processo de criação do conhecimento perfeito; do explícito para o explícito, sistematizando-se conceitos em um sistema de conhecimento, incluindo a combinação de diferentes conjuntos de conhecimento explícito; e do explícito para o tácito, quando se recorre ao procedimento da dedução.

Todavia, não é suficiente para uma organização que ela crie conhecimento. Esse conhecimento precisa ser selecionado e armazenado para que possa ser utilizado pela organização sempre que for necessário. E, para armazenar o conhecimento, é preciso, antes, que a organização saiba armazenar a informação e organizá-la. A informação armazenada representa um componente importante e freqüentemente consultado da memória da organização. E a construção do conhecimento faz uso dos sistemas de armazenamento de informações para localizar fontes de experiência dentro da organização e recuperar relatórios de trabalhos anteriores ou problemas semelhantes.

Uma vez armazenado o conhecimento, passa-se para a etapa da utilização desse conhecimento. Sem essa etapa, a gestão do conhecimento se torna inefetiva, pois se a empresa não aplicar seu novo conhecimento, não conseguirá nenhum benefício e o esforço de armazenagem não produzirá qualquer efeito positivo. Todos os elementos construtivos da gestão do conhecimento necessitam ser dirigidos para a utilização eficiente do conhecimento individual e organizacional no intento de atingir as metas da empresa.

Essa utilização pode se dar por meio do compartilhamento do conhecimento, sendo relevante reconhecer que não adianta dispor de conhecimentos importantes se não se promove a sua partilha. A organização somente se beneficia como um todo quando o conhecimento é difundido, transferido, compartilhado e alavancado.

Importa salientar ainda, brevemente, que a Gestão do Conhecimento apresenta vinculação direta com a gestão do capital intelectual de uma organização, ou seja, aquele 
capital que resulta da combinação de ativos intangíveis, fruto das mudanças nas áreas da tecnologia da informação, mídia e comunicação, que trazem benefícios intangíveis para as empresas e que capacitam seu funcionamento. O capital intelectual se constitui em

modalidade de conhecimento armazenado, contribuindo essencialmente para o desenvolvimento organizacional.

\section{REFERÊNCIAS}

ANTUNES, Maria Thereza Pompa. Capital intelectual. São Paulo: Atlas, 2000.

BASIL, D.; COOK, C. O empresário diante das transformações sociais, econômicas e tecnológicas. São Paulo: McGraw-Hill do Brasil, 1978.

BROCKA, Bruce M.; BROCKA, Suzanne. Gerenciamento da qualidade. São Paulo: Makron Books, 1994.

CANTANHEDE, G. Administração e gerência: do artesanato à automação. Rio de Janeiro: FGV, 1980.

CHAMPION, D.J. A sociologia das organizações. São Paulo: Saraiva, 1979.

DAVIS, Keith; NEWSTROM, John W. Comportamento humano no trabalho. São Paulo: Pioneira, 1992.

DRUCKER, Peter F.. A Prática da Administração de Empresas. São Paulo: Editora Pioneira, 1981.

DUTRA, Joel Souza. Administração de carreira: uma proposta para repensar a gestão de pessoas. São Paulo: Atlas, 1996.

FLEURY, Afonso; FLEURY Maria Tereza Leme. Estratégias empresariais e formação de competências: um quebra-cabeça caleidoscópico da indústria brasileira. 3 ed. São Paulo: Atlas, 2004

GONÇALVES, J. E. L. Os impactos das novas tecnologias nas empresas prestadoras de serviços. RAE - Rev. Adm. Emp. São Paulo, v. 34, n. 1, p.63-81, jan/fev. 1994.

HALL, R. H. Organizações: estruturas e processos. 3. ed. Rio de Janeiro: Prentice Hall do Brasil, 1984.

HESKETH, José Luiz. Desenvolvimento organizacional. São Paulo: Atlas, 1977.

KUMAR, Krishan. Da sociedade pós-industrial à pós-moderna: novas teorias sobre o mundo contemporâneo. Rio de Janeiro: Jorge Zahar, 1997.

LARA, Consuelo Rocha Dutra de. A atual gestão do conhecimento: a importância de avaliar e identificar o capital humano nas organizações: São Paulo: Nobel, 2004. 
MCKENNA, Regis. Marketing de relacionamento. Rio de Janeiro: Campus; São Paulo: Publifolha, 1999.

NASSAR, Paulo; FIGUEIREDO, Rubens. O que é comunicação empresarial. São Paulo: Brasiliense, 1995.

RATTNER, H. Informática e sociedade. São Paulo: Brasiliense, 1985.

RAYNAL, Serge. A gestão por projectos. São Paulo: Instituto Piaget, 1996.

RESENDE, Enio. O livro das competências: desenvolvimento das competências: a melhor autoajuda para pessoas, organizações e sociedade. 2. ed. Rio de Janeiro: Qualitymark, 2003.

RODRIGUES, S. B. et al. Tecnologia da informação nos serviços: o impacto na configuração do trabalho. RAE - Rev. Adm. Emp., Rio de Janeiro, v. 26, n. 1, p. 43-56, jan/mar 1986.

TEBOUL, James. Gerenciando a dinâmica da qualidade. São Paulo: Qualitymark, 1991.

TOWSEND, Patrick. Compromisso com a qualidade: um sistema comprovado de melhoria da qualidade. Rio de Janeiro: Campus, 1991.

VIEIRA, Adriane. A qualidade de vida no trabalho e o controle da qualidade total. Florianópolis: Insular, 1996.

ZABOT, João Batista M.; SILVA, L. C. Mello da. Gestão do conhecimento: aprendizagem e tecnologia, construindo a inteligência coletiva. São Paulo: Atlas, 2002. 